\title{
Leiden Mutation, Bed Rest and Infection: Simultaneous Triggers for Maternal Deep-Vein Thrombosis and Neonatal Intracranial Hemorrhage?
}

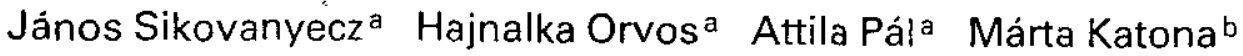 \\ Emōke Endreffy ${ }^{c}$ Emese Horváth ${ }^{c}$ János Szabó ${ }^{c}$ \\ Departments of a Obstetrics and Gynecology, ${ }^{b}$ Pediatrics and ${ }^{c}$ Medical Genetics, University of Szeged, \\ Faculty of Medicine, Albert Szent-Györgyi Medical and Pharmaceutical Center, Szeged, Hungary
}

\section{Key Words}

Leiden mutation . Vein thrombosis . Neonatal

intracranial hemorrhage

\begin{abstract}
The possible etiologic roles of infection and bed rest are discussed in connection with a case of maternal homozygous Leiden mutation leading to prematurity, maternal deep-vein thrombosis and neonatal intracranial hemorrhage in a heterozygous premature baby. Maternal bacterial infection and bed rest may trigger deep-vein femoral thrombosis in women with a homozygous Leiden mutation on tocolytic therapy for the treatment of premature labor. The neonate carrying at least one mutated allele of factor $V$ Leiden might be at risk for the development of intracranial hemorrhage.
\end{abstract}

Copyright $\$ 2004$ S. Karger AG, Basel

\section{Introduction}

Maternal and neonatal thrombotic events are severe complications in the perinatal period and are responsible for a significant proportion of the maternal and neonatal morbidity and mortality. The incidence of venous thrombotic complications associated with pregnancy ranges

\begin{tabular}{|c|c|}
\hline KARGER & $\begin{array}{l}\text { (2004 S. Karger AG, Base] } \\
1015-3837 / 04 / 0193-0275 \$ 21.00 / 0\end{array}$ \\
\hline $\begin{array}{l}\text { Fax + } 41613061234 \\
\text { E-Mail karger@karger.ch } \\
\text { unemw karoermm }\end{array}$ & $\begin{array}{l}\text { Accessible online at: } \\
\text { www karper com } / \text { fidt }\end{array}$ \\
\hline
\end{tabular}

from 0.68 to 1.00 per 1,000 deliveries in different studies [1]. The Leiden mutation is characterized by an inherited resistance to activated protein C (APC). As a consequence of this mutation, the factor $\mathrm{V}$ coagulation protein will predispose to thrombosis [2]. The prevalence of this mutation in different populations ranges from 2 to $7 \%$ [3]. Furthermore, it has been demonstrated that APC resistance is a very common disorder, found in $30-60 \%$ of cases with familial thrombophilia [3].

A number of reports have documented the relationship between factor $V$ Leiden and maternal $[2,4-8]$ or fetal complications of pregnancy [9-13]. This mutation provides a basic risk of an undesirable pregnancy outcome. If other predisposing factors, such as perinatal infection and bed rest, are coupled with a factor $V$ Leiden mutation, the risk of thrombosis may be increased.

This paper concerns a woman with a homozygous Leiden mutation. Her pregnancy provides evidence for the thrombotic role of the Leiden mutation, with the hypothesis that the thrombosis was triggered by perinatal infection and bed rest.

\section{Case Report}

A nonsmoking woman (age: 23 years, $G: 1$ ) with a singleton pregnancy at 29 weeks of gestation was hospitalized with uterine contractions, confirmed by cardiotocography. The ultrasonographic biomet* 
rics revealed a fetus appropriate for gestational age. On the day of admission, the length of the cervix was $1 \mathrm{~cm}$ and the diameter was $2 \mathrm{~cm}$, estimated by palpation. The white blood cell count was $13,000 \mu^{-1}$ and C-reactive protein level was below $5 \mathrm{mg} \mathrm{liter-1}^{-1}$. Bed rest was prescribed, an intravenous infusion of a $\beta_{2}$ mimetic was administered to terminate the uterine contractions and an intramuscular injection of $10 \mathrm{mg}$ dexamethasone was applied for respiratory distress syndrome prophylaxis. The vaginal microbial culture revealed Enterococcus faecalis infection, and antibiotic therapy (sulbactam/ ampicillin) was initiated. The uterine contractions stopped and the next 10 days were uneventful. A repeated vaginal microbiological test 8 days after the antibiotic therapy was negative. The repeated white blood cell count was $9,200 \mu \mathrm{l}^{-1}$. The woman remained hospitalized and 15 days later, in week 32 of gestation, she complained of left inguinal pain. The body temperature $\left(38.0^{\circ} \mathrm{C}\right)$ and the pulse rate $\left(95 \mathrm{~min}^{-1}\right)$ were measured. The white blood cell count was $14,300 \mu 1^{-1}$, the $\mathrm{C}$-reactive protein level was elevated over $25 \mathrm{mg} \mathrm{liter}^{-1}$ and the level of the D-dimers was $30 \mu \mathrm{g} \mathrm{ml}^{-1}$. A blood pressure of $110 / 70 \mathrm{~mm} \mathrm{Hg}$, a platelet count of $300,000 \mathrm{ml}^{-1}$, an activated partial thromboplastin time of $33,3 \mathrm{~s}$, a bleeding time of $70 \mathrm{~s}$, and a coagulation time of $245 \mathrm{~s}$ were measured. Coagulation studies revealed no IgM or IgG anticardiolipin antibodies in the mother. She had normal levels of antithrombin III, protein $\mathrm{C}$, total and free protein S, factor XII, fibrinogen, plasminogen, and normal fibrin plate lysis. Ultrasound examination of the left lower extremity indicated a thrombosis in the vena femoralis communis and in the proximal part of the vena superficialis. Blood flow was not detected in this part of the vein, and a decreased blood flow was measured in the distal part of the vena femoralis superficialis, the vena poplitea, and the vena tibialis anterior and posterior. After the diagnosis of deep-vein thrombosis, the patient was treated with heparin, and antibiotics were restarted. Ca-heparin was administered to achieve a 2 times higher maternal activated thromboplastin time. Five days after confirmation of the deep vein femoral thrombosis, the mother still had fever, and her uterine contractions restarted. The maternal white blood cell count was $15,600 \mu \mathrm{l}^{-1}$. The $\mathrm{C}$-reactive protein level was $28 \mathrm{mg}$ liter $^{-1}$. Repeated intravenous tocolysis was unsuccessful and a 2,350 g preterm male child was delivered vaginally. The infant seemed to be healthy, with Apgar scores of 7 at $1 \mathrm{~min}$, and 8 at $5 \mathrm{~min}$. The placenta appeared normal on visual inspection, but was not subjected to pathologic analysis. After birth, the infant developed tachypnea and the chest X-ray images demonstrated RDS, so he was transferred to the Neonatal Intensive Care Unit (NICU). From postpartal day 3, progressive intracranial hemorrhage was observed in the boy by cranial sonography, without signs of superior sagittal sinus thrombosis. A computed tomography scan of the head on the next day revealed intraventricular hemorrhage in the right hemisphere. A repeated image showed a 1- to $1.5-\mathrm{cm}$ wild hyperechogenic fold around the lateral ventricles and a $1.5-\mathrm{cm}$ diameter fluid decomposition under the gyrus cinguli. The diagnosis was hemorrhagic intracranial infarction. As a consequence of the intracranial hemorrhage, hydrocephalus developed. The increasing intracranial pressure was decreased by a ventriculo-atrial shunt. The premature baby was discharged 97 days after delivery. At the age of several months, he required hospitalization because of seizures. The neurologic examination confirmed the diagnosis of epilepsy and he has subsequently been treated with anticonvulsive drugs. Because of the symptoms of increased intracranial pressure (vomiting, drowsiness and fever), shunt revision has been performed by surgeons on several occasions.

At the time of publication, the child is somatically mildly underdeveloped: his weight is $19 \mathrm{~kg}$. He has a number of signs of mental and motor retardation. He is blind, but his blindness cannot be attributed to previous retrolentar fibroplasia. $\mathrm{He}$ is unable to attend normal school, and is at home under devoted maternal care.

Since the thrombotic event, the mother is healthy. Lifestyle modification, diet and regular exercise was advised her to prevent vein thrombosis.

After the delivery, maternal bed rest and anticoagulant therapy were continued. On postpartal day 2, the mother experienced left renal pain. Pyuria and leukocytosis in the urine were detected, and accordingly cefalexin therapy was started. The urinary bacteriological culture after antibiotic administration was negative. On postpartal day 23, an upper airway infection developed, but disappeared 4 days later. On postpartal day 34 , repeated Doppler examinations of the femoral veins showed an improvement of the circulation in the $v$. femoralis. The recanalization of the veins was completed and the mother was discharged 38 days after delivery. In 1999, 5 years after the pregnancy, genetic testing for factor $V$ Leiden revealed a homozygous mutation in the mother and a heterozygous mutation in the child. No other thrombophilic mutation was detected.

\section{Discussion}

Women who carry the factor V Leiden mutation are at increased risk of developing deep-venous thrombosis, miscarriage and other severe maternal and fetal complications $[2,4,5]$. Pregnancy is a prothrombotic state in which increased levels of coagulation factors and a decrease in fibrinolysis are well documented. These physiological changes are important in minimizing the risk of blood loss at delivery. The phenomenon is likely to contribute to the increased risk of venous thrombosis during this period [6, 7]. The association between factor $\mathrm{V}$ mutation and deepvein thrombosis in the mother during and after pregnancy is well established, as are the neonatal complications and hereditary coagulation abnormalities. The clinical observations suggest that infection also predisposes to thrombosis, and various evidence has been published about the relationship between infection and prematurity [14].

Erhardt et al. [13] found a high prevalence of factor V Leiden mutation in mothers of premature neonates. The association between the factor $\mathrm{V}$ mutation and neonatal intracranial hemorrhage was reported by Melegh et al. [9]. Broxterman et al. [12] described a woman who had suffered a motor vehicle accident 10 days before delivery, which was suspected to be a factor predisposing to fetal thrombosis in case of Leiden mutation. Kovacevich et al. [15] observed a higher prevalence of thrombotic events among women after extended bed rest prescribed as part of the treatment for premature labor or the premature rupture of membranes.

In this paper, we present a woman with a homozygous Leiden mutation who transmitted one allele to her baby. 
The maternal infection (indicated by the fever, elevated white blood cell count and C-reactive protein level), and recommended bed rest were considered to have triggered deep-vein thrombosis in this woman with the homozygous Leiden mutation.

Severe intracranial hemorrhage and hydrocephalus developed in the premature infant. A possible etiology was that the prematurity and the increased genetic susceptibility to thrombotic events might have resulted in microthrombosis in the periventricular veins. The leukomalacia and intraventricular hemorrhage were the consequences of the disturbed perfusion in the periventricular area.

Naturally, a single case report cannot prove our supposition, and further studies are necessary to address the neonatal consequences of factor $\mathrm{V}$ Leiden mutation. It is also important to remember that the case reported here was observed in 1994. Today, new and safer treatment regimes are available, e.g. low-molecular-weight heparin instead of unfractionated heparin [1]. Prolonged heparin therapy is known to be associated with a number of maternal risk factors, such as osteoporosis and thrombocytopenia [1]. The fetal risk of heparin is negligible because studies suggest a very low transplacental diffusion rate; accordingly, this cannot be the reason for neonatal intracranial hemorrbage [16].

Women with a previous episode of venous thromboembolism who are currently not on anticoagulants, those with a protein $\mathrm{C}$ deficiency plus a family history of venous thromboembolism, those who are homozygous for a factor V Leiden or a prothrombin mutation, and those with combined thrombophilias are considered at high risk of venous thromboembolism. In accord with McColl et al. [1], we now manage such patients with once-daily lowmolecular-weight heparin. Thromboprophylaxis is introduced 4-6 weeks ahead of the gestational stage at which the event occurred in the previous pregnancy, or at 24 weeks of gestation in the others.

As the message of this case report, we presume that women with a homozygous Leiden mutation are at increased risk of developing deep-vein thrombosis during pregnancy, especially if infection and bed rest are present simultaneously. Their infants who carry the mutation, at least in the heterozygous state, are also at risk of thrombotic complications such as intracranial hemorrhage. In recent years Leiden or other thrombophilic mutations have been known in advance in an increasing number of pregnant women. These women need an additional pregnancy care, especially when infection is present or bed rest is advised to prevent pregnancy complications. Women with deep-vein thrombosis during pregnancy, and also their babies, should be tested for markers of thrombophilia, because the molecular diagnosis can direct our attention to the need for the prevention of severe maternal and fetal thrombotic complications.

\section{References}

1 McColl MD, Walker LD, Greer IA: The role of inherited thrombophilia in venous thromboembolism associated with pregnancy. $\mathrm{Br} \mathrm{J} \mathrm{Ob}$ stet Gynaecol 1999;106:756-766.

2 Dizon-Townson DS, Nelson LM, Jang $H$, Varner MW, Ward K: The incidence of factor $\mathrm{V}$ Leiden mutation in an obstetric population and its relationship to deep vein thrombosis. Am J Obstet Gynecol 1997;1 176:883-886.

3 Bauer KA: Management of patients with hereditary defects predisposing to thrombosis including pregnant women. Thromb Haem 1995; 74:94-100.

4 Kupferminc MJ, Eldor A, Steinman N, Many A, Bar-Am A, Jaffa A, Fait G, Lessing J: Increased frequency of genetic thrombophilia in women with complications of pregnancy. $\mathrm{N}$ Engl J Med 1999;340:9-13.

5 Rai RS, Regan L, Chitolie A, Donald JG, Cohen $\mathrm{H}$ : Placental thrombosis and second trimester miscarriage in association with activated protein C resistance. Br J Obst Gynaecol 1996;103:842-844.

6 Grandone E, Margaglione M, Colaizzo D, D'Andrea G, Cappucci G, Brancaccio V, Di Minno G: Genetic susceptibility to pregnancy- related venous thromboembolism: Roles of factor V Leiden, prothrombin G20210A, and methylenetetrahydrofolate reductase C677T mutations. Am J Obstet Gynecol 1998;179: 1324-1328.

7 Hellgren M, Svensson PJ, Dahlbäck B: Resistance to activated protein $\mathrm{C}$ as a basis for venous thromboembolism associated with pregnancy and oral contraceptives. Am J Obstet Gynecol 1995;173:210-213.

8 Pauer HU, Neesen J, Schlosser M, Hinney B, Rauskolb R: Homozygous factor V Leiden mutation in woman with multiple adverse pregnancy outcomes. Arch Gynecol Obstet 2000; 264:164-165.

9 Melegh B, Stankovics J, Kis A, Nagy Á, Storcz $\mathrm{J}$, Losonczy H, Méhes K: Increased prevalence of factor $\mathrm{V}$ Leiden mutation in neonatal intracranial haemorrhage. Eur J Pediatr 1998;157: 261.

10 Varelas PN, Sleight BJ, Rinder HM, Sze G, Ment LR: Stroke in a neonate heterozygous for factor V Leiden. Pediatr Neurol 1998 Mar; 18 : 262-264.

11 Hagstrom JN, Walter J, Bluebond-Langner R, Amatniek JC, Manno Cs, High KA: Prevalence of the factor $\mathrm{V}$ Leiden in children and neonates with thromboembolic disease. J Pediatr 1998; 133:777-781.

12 Broxterman KJ, Mathew P, Chicoine L: Left brachial artery thrombus, left axillary vein thrombus, and stroke in a neonate with factor V Leiden mutation. J Pediatr Hematol Oncol 2000;22:472-475.

13 Erhardt E, Stankovics J, Molnár D, Adamovich K, Melegh B: High prevalence of factor V Leiden mutation in mothers of premature neanates. Biol Neonate 2000; 78:145-146.

14 Kenyon S, Boulvain M, Neilson J: Antibiotics for preterm premature rupture of membranes (Cochrane Review). Cochrane Database Syst Rev 2001;4:CD001058.

15 Kovacevich GJ, Gaich SA, Lavin JP, Hopkins MP, Crane SS, Stewart J, Nelson D, Lavin LM: The prevalence of thromboembolic events among women with extended bed rest prescribed as part of the treatment for premature labour or preterm premature rupture of membrane. Am J Obstet Gynecol 2000;182:1089-1092.

16 Schneider H, Malek A: Lack of permeability of the human placenta for erythropoietin. J Perinat Med 1995;23:71-76.
Leiden Mutation, Infection, Bed Rest, Vein Thrombosis, Neonatal Intracranial Hemorrhage
Fetal Diagn Ther 2004;19:275-277 